RodrígueZ PEÑARANDA, M. L., «El debido proceso con enfoque de género en Colombia », REDUR I6, diciembre 20I8, págs. I2I-I42. ISSN I695-078X. doi: Io.I8I72/redur.4232

\title{
EL DEBIDO PROCESO CON ENFOQUE DE GÉNERO EN COLOMBIA
}

\author{
María Luisa RODRÍGUEZ PEÑARANDA ${ }^{\mathrm{T}}$ \\ CATEDRÁTICA EN DERECHO CONSTITUCIONAL COLOMBIANO \\ UNIVERSIDAD NACIONAL DE COLOMBIA. CAMPUS BOGOTÁ
}

SUMARIO: I. INTRODUCCIÓN. II. El ANDAMIAJE DEL DEBIDO PROCESO Y LA IGUALDAD ANTE LA LEY. III. DEBido PROCESO CON ENFOQUe DE GÉNERO. III.I. El PRINCIPIO DE DEBIDA DiligenCiA. III.2. LA GARANTÍA DE UN RECURSO JUDICIAL EFECTIVO. III.3. OBLIGACIÓN DE INVESTIGAR. III.4. OBLIGACIÓN DE JUZGAR, CASTIGAR Y REPARAR. IV. EL MÉTODO FEMINISTA DEL POSICIONAMIENTO DE BARTLETT. V. CONCLUSIÓN. VI. BIBLIOGRAFÍA.

RESUMEN: El derecho fundamental al debido proceso ha sido una de las principales conquistas jurídicas en la protección de los individuos frente al abuso del poder y la injusticia. Este macro derecho reúne una serie de etapas, procedimientos y conjunto de garantías que tras ser respetadas permite culminar con una decisión jurídica y socialmente valorada como justa. No obstante, las dinámicas y modus operandi que rodean las violencias de género, principalmente en el ámbito privado y sin testigos válidos, desafía la manera en que hasta hace poco era entendido el material probatorio adecuado para evidenciar la vulneración de los derechos. En este artículo se analiza cómo en virtud de los desarrollos de los derechos humanos de las mujeres a una vida libre de violencias, y de conformidad con las convenciones internacionales como la CEDAW y la Convención Belém do Pará, el enfoque de género aplicado al debido proceso alberga un triple contenido sustancial, procedimental y metodológico. Así se exige a las y los funcionarios judiciales prestar atención a cómo los estereotipos sexistas afectan a las mujeres en el acceso a la justicia; que las pruebas tradicionales sean acompañadas de un nuevo material como perfiles psicológicos y psiquiátricos; la aplicación de metodologías investigativas que den cuenta del contexto que produce la violencia y las relaciones de poder que gestan las situaciones de subordinación entre los géneros. Además, se precisa que en los Estados reposa la carga de investigar, sancionar y reparar a las víctimas de conformidad al principioderecho a la debida diligencia. Por último, se propone crear puentes teóricos entre las metodologías feministas y el derecho, para lo cual se analiza el método del posicionamiento planteado por la académica estadounidense Katharine Bartlett.

PAlabras Clave: género, discriminación contra las mujeres, debido proceso, interseccionalidad, enfoque de género, derecho a una vida libre de violencia, derecho a la debida diligencia, estereotipos sexistas, métodos feministas, derechos humanos de las mujeres, roles de género, discriminación estructural, el género como retórica, el método del posicionamiento, razonamiento práctico feminista, verdades situadas

\footnotetext{
${ }^{\mathrm{I}}$ Doctora en derecho constitucional, profesora asociada, Directora del Observatorio Nacional de Justicia Real -ONJURE-, Facultad de Derecho, Ciencias Políticas y Sociales, Universidad Nacional de Colombia.
} 


\section{THE DUE PROCESS WITH GENDER FOCUS IN COLOMBIA}

ABSTRACT: The fundamental right to due judicial process has been one of the main legal achievements in the search of protection of individuals against the abuse of power and injustice. This big field of the law brings together a series of stages, procedures and a set of judicial guarantees that, after being warranted, allows us to reach a legal decision that can be considered as reliable and fair. However, the dynamics and modus operandi that surround gender violence, challenge the way in which, until recently, appropriate evidentiary material to show the violation of rights was understood, particularly in the private sphere because there are no witnesses. This article analyses how, under the development of women's human rights towards a life free of violence, a gender approach applied to due judicial process there is a combined substantive procedural, and methodological content. All this in accordance with international conventions such as CEDAW and the Belém do Pará Convention. Judicial officers are required to pay attention to how gender stereotypes affect women by making more difficult to access to justice; it is required that traditional tests are accompanied by new methods such as psychological and psychiatric profiles; and finally, it is also necessary to implement research methodologies that show the context that produces violence and power relations that generate situations of subordination between genders. In addition, it is stated that the States are responsible for investigating, punishing and compensating victims in accordance with the principle/right to due diligence. Finally, it is proposed to create theoretical links between feminist research methodologies and law, for which the Positionality method proposed by the American academic Katharine Bartlett is analysed.

KEYwORDS: Gender, discrimination against women, due judicial process, intersectionality, gender approach, he right to a life free from violence, right to due diligence, gender stereotypes, feminist methods, women's human rights, gender roles, structural discrimination, gender as rhetoric, positionality method, practical feminist reasoning.

\section{Introducción}

El enfoque de género en el derecho es entendido como una herramienta de interpretación que toma en consideración las relaciones de poder gestadas a partir del género o sexo, y en especial, las desigualdades que tales asignaciones propician o crean en la sociedad, con el fin de mitigarlas, neutralizarlas o compensarlas. Todo ello de conformidad con la cláusula de igualdad y no discriminación consagrada en el artículo I3 de la Constitución de Colombia.

Tanto el derecho internacional como el nacional han identificado una amplia gama de factores considerados sospechosos de discriminación, como la raza, la etnia, la clase, el origen nacional, la lengua, el género o sexo, entre otros. Estos factores suelen producir, desde desventajas socioeconómicas, marginalidad o exclusión, hasta prácticas condenadas por el derecho internacional de los DDHH como el exilio o el exterminio.

La identificación de los grupos, colectivos o poblaciones en las que frecuentemente recaen factores de discriminación ha revelado que éstos tienden a imbricarse en un mismo sujeto, denominados por la Constitución como sujetos de especial protección, los cuales requieren de enfoques diferenciales para ser receptores de políticas públicas que busquen superar la brecha de desigualdad histórica, sin desconocer su identidad y necesidades concretas.

En tanto que la primera es una herramienta jurídica que identifica individuos pertenecientes a poblaciones vulnerables, la segunda demanda que las políticas públicas impulsadas para corregir las desigualdades de ciertos colectivos no sean ciegas a las 
diferencias, de modo que una y otra herramienta conceptual se necesitan y complementan para la realización del mismo fin: promover la igualdad real entre los individuos sin menoscabar el reconocimiento de su identidad. El engranaje que configuran ambos conceptos: sujetos de especial protección y enfoques diferenciales es lo que he venido denominando las tenazas de la igualdad².

Aunque el diseño constitucional pareciera identificar grupos poblacionales con un solo factor de discriminación común, en ocasiones generando el surgimiento de identidades estratégicas y/o disputas identitarias en aras de obtener una ayuda económica concreta adaptable a la oferta de beneficios económicos estatales (en ocasiones, mujer cabeza de hogar, negra o desplazada según convenga). La mirada interseccional como aporte del feminismo negro estadounidense ${ }^{3}$ en el marco de los Critical Legal Studies, vendría a complementar los enfoques diferenciales y su tendencia a la esencialización. Estos aportes subrayan cómo puede generarse la superposición entre distintos factores de discriminación, principalmente entre la raza, el género y la clase, dando lugar a situaciones de discriminación mayores o particulares soterradas en el interior de uno o varios colectivos. Así sucede, por ejemplo, con las mujeres negras frente a los reclamos del colectivo afroestadounidense que identifica a los hombres como víctimas del discurso de la supremacía del hombre blanco, pero que en el marco de ese discurso masculiniza la opresión invisibilizando a las mujeres negras, las cuales tampoco se ven reflejadas en las necesidades y reclamos de las mujeres blancas ${ }^{4}$.

Ahora bien, en el presente documento analizaré cómo el enfoque de género ha sido considerado como una herramienta propia del derecho sustancial que si bien involucra la interpretación de los derechos, se encuentra fuertemente alejada de la parte más procedimental o de aplicación cotidiana por los operadores jurídicos dentro y fuera de los despachos judiciales. Al parecer, la práctica procesal suele hacer oídos sordos de estas discusiones y sigue considerando que tales enfoques tienen poco o nada que aportar al proceso judicial, administrativo o disciplinario.

Por el contrario, en el presente trabajo defenderé cómo el enfoque de género, aplicado siempre desde una mirada interseccional en las políticas de reconocimiento más no en las de redistribución, debe ser considerado en todas las prácticas procesales pertenecientes a la solicitud, decreto, práctica y valoración del material probatorio, como etapa previa e indispensable para la adjudicación de los derechos.

${ }^{2}$ El concepto de tenazas de la igualdad lo formulé en «Dejando atrás la constitución del litigio incluyente: el reto de la paz como bienestar social». Pensamiento Jurídico, 43, enero-junio, Bogotá, 2016, pp. 349-375.

${ }^{3}$ Kemberlé Crinshaw sería la abogada afrodescendiente estadounidense que nominó el fenómeno ya detectado por las feministas contribuyendo a su análisis y difusión. Para ello usó la metáfora de la intersección como cruce de dos vías o caminos, en cuyo encuentro se invisibiliza la particularidad que se genera cuando un sujeto reúne más de un factor de discriminación, particularmente raza y género como las mujeres negras, al que pronto se sumarían las latinoamericanas (feminismo chicano), mujeres del tercer mundo (feminismo poscolonial), inmigrantes. Bajo el argumento feminista de que lo que no tiene nombre no puede comprenderse ni superarse. CRENSHAW, Kimberlé, «Mapping the margins: Intersectionality, identity politics, and violence against women of color», Stanford Law Review, 43, July I99I, pp. I24I-I299.

${ }^{4}$ Para una mayor profundización sobre el origen del concepto jurídico de interseccionalidad y su difusión en las ciencias sociales; así como sus variables teóricas, contradicciones y críticas, Vid. Viveros, Mara, «La interseccionalidad, una aproximación situada a la dominación», Revista Debate Feminista, 52, 20I6, pp. I-I7, descargable en http://debatefeminista.cieg.unam.mx/. 
Argumentaré cómo mientras el enfoque de género no sea implementado en la comprensión y práctica del derecho fundamental al debido proceso, el acceso a la justicia y el derecho a una decisión eficaz seguirá siendo fuertemente esquiva para las mujeres, niños, niñas y adolescentes.

Para ello, el artículo se encuentra dividido en tres partes, en la primera de ellas recordaré las bases del principio/derecho al debido proceso e intentaré dilucidar sobre cómo la imparcialidad que lleva ínsito dicho derecho puede llegar a validar la apatía e indiferencia de las y los jueces frente al sufrimiento de la mitad de la humanidad, y más en concreto, de las mujeres o los seres feminizados. En la segunda parte haré una breve presentación sobre el concepto más instrumental de género, sin profundizar sobre las identidades de nacimiento y su transición hacia otras, dejando de lado la muy importante discusión sobre la apuesta por su deconstrucción como estrategia asumida por algunas feministas queer, para derrumbar el edificio de la discriminación, tema que desviaría la atención principal que quiero brindarle a este texto 5 . En vez de ello, intentaré profundizar en un concepto básico, como herramienta de partida que nos permita entender cómo dicho dispositivo, al sumarse al debido proceso, no genera una mera subsunción, sino una verdadera ruptura con la manera como hasta el momento hemos entendido dicho derecho fundamental, ahora reconfigurado con el enfoque de género. Por último y como tercer aspecto, traeré a colación el método feminista planteado por Katherine T. Bartlett conocido como «el posicionamiento» por considerarlo sumamente apropiado para el abordaje del proceso judicial desde la experiencia feminista. El método del posicionamiento revela el gran desafío que para los y las jueces supone transgredir el conformismo, la pasividad e impunidad que hasta el momento ha arropado a la rama judicial en la prevención, investigación, judicialización, sanción y reparación de la discriminación y violencias contra las mujeres.

\section{El andamiaje del debido proceso y la igualdad ante la ley}

La contundente idea de que nadie puede ser condenado sin haber sido previamente vencido en un juicio justo es el fundamento del principio/derecho al debido proceso. La fuerza de esta idea surge con la firme intuición de que una sociedad justa es aquella en la que las leyes que confiscan bienes mediante tributos y ordenan ir a la guerra se apliquen a todos sin distinción ni privilegios, es decir que todos los súbditos satisfagan de la misma manera las cargas de sostenimiento del Estado especialmente las económicas y armadas. Con la superación del antiguo régimen, esta idea se consolidará bajo la aspiración de construir una sociedad en la que se aplique la igualdad de trato ante la ley, sea esta desfavorable (en las cargas u obligaciones) o favorable (en los derechos).

¿Cuándo hablamos de un proceso justo? Si bien el derecho no pretende arribar a la construcción de un relato que dé cuenta de toda la información disponible para construir la verdad, como lo hace un(a) historiador(a), los/las jueces y abogados, circunscritos al marco de un proceso judicial con dos partes determinadas, buscan obtener elementos de juicio que permitan esclarecer los hechos objeto de investigación en igualdad «de armas». Con este fin utilizan todo de lo que se pueda disponer para condenar al acusado por parte de la

\footnotetext{
${ }^{5}$ Al respecto, ver BUTLER, Judith, Deshacer el género. Paidós Studio I67, Barcelona, 2006.
} 
víctima, o exonerarlo de toda responsabilidad, por parte de la defensa. El denominador común con el que cuentan ambas partes es el material probatorio recaudado y valorado bajo un halo de objetividad e imparcialidad judicial.

El aparato judicial ofrece entonces una serie de garantías dirigidas a rodear de la máxima objetividad, imparcialidad y transparencia al proceso mismo, para que cada una de las partes pueda, sin distinción, contar con un cúmulo de derechos que le son funcionales al rol contradictor que ocupa dentro del proceso o actuación administrativa.

Así surgen los derechos a ser juzgado conforme a las leyes preexistentes al acto que se le imputa (principio de legalidad y tipicidad); ante un juez o tribunal competente (que excluye, por ejemplo, el juicio de civiles ante tribunales militares); con observancia a la plenitud de las formas propias de cada juicio (respeto y evacuación de cada una las etapas y términos procesales con previa notificación); bajo la presunción de inocencia del acusado; con derecho de defensa y a la asistencia técnica escogida, o de oficio, durante la investigación y juzgamiento; a un proceso sin dilaciones injustificadas; al principio de favorabilidad de la ley penal; a solicitar pruebas y controvertirlas; a impugnar la sentencia condenatoria y a no ser juzgado dos veces por el mismo hecho (non bis in ídem). Además, otros principios (por ejemplo, in dubio pro reo (la duda favorece al reo) o el del juez natural, entre otros) contribuyen a orientar el proceso con una perspectiva hermenéutica de máxima garantía para los enjuiciados y las víctimas. De suerte que ambos conceptos, el derecho al debido proceso y la igualdad ante la ley. son los pilares de la justicia en el marco de una democracia constitucional.

Dentro de la iconografía que acompaña esta pretensión de objetividad, imparcialidad y transparencia en el proceso judicial, dos símbolos han sido construidos para transmitir dichos postulados: i) la imagen de la justicia con los ojos vendados y ii) la toga. En la primera de ellas, la justicia se evoca en cuerpo de mujer, de pie, en una de sus manos eleva una balanza y en la otra, blande una espada, lo que sugiere la ecuanimidad de la decisión y la sanción implacable ante el desobedecimiento a la ley. Pero todo esto sucede mientras tiene sus ojos vendados, de ahí la frase común de que la justicia es ciega. Al ignorar quienes se someten a ella en cuanto a sus condiciones sociales, de clase, género, origen, nacionalidad, lengua, religión, edad, raza o etnia, decide con el mismo rasero y sin contemplaciones particulares que la distraerían de lo verdaderamente importante: aplicar la ley en igualdad.

En segunda medida se encuentra la toga, ese traje oscuro, masculino, largo, sin decorados ni formas que tiene por objeto ocultar la humanidad del juzgador; detrás de este manto queda la historia personal y las condiciones de los individuos, su biografía, sus experiencias, debilidades, gustos, preferencias, para dar paso al funcionario imparcial, que desconociéndose así mismo se encuentra apto para conocer a los otros ${ }^{6}$.

\footnotetext{
${ }^{6}$ El uso de la toga, propia de los universitarios ingleses, se popularizó durante la revolución francesa al ser elegida como la pieza que vestiría uniformemente al tercer estado o pueblo llano, distinguiéndolos frente al clero - primer estado- y la nobleza -segundo- quienes habrían de vestir el atuendo apropiado a su rango particular dentro del orden al que pertenecían. El traje del tercer estado consistía en una capa de tela negra «peor incluso que la clase más baja de togados en las universidades inglesas» aseguró un doctor inglés. Vid. MC PHEE, Peter, La Revolución Francesa, 1789-1799. Una nueva historia. Crítica, Libros de historia, Barcelona, 2002, p. 65 .
} 
A diferencia del velo de la ignorancia de Rawls, en su célebre Teoría de la Justicia, aquí el juez ciego y sin humanidad no es parte de ningún acuerdo, no se encuentra en igualdad con los procesados, ni tiene interés en la forma como se resuelva la decisión (lo que generaría un conflicto de interés, proscrito en la actuación judicial). El juez, observador pasivo, se encuentra en un peldaño superior, pues de su libre convencimiento plasmado en una decisión, penden las partes. La toga además neutraliza el género del funcionario porque esconde las formas femeninas y los órganos de identidad sexual, por lo cual se espera que la justicia sea asexuada, aunque la terminología militar que rodea el proceso -«igualdad de armas»- pareciera establecer un tablero de juego marcado por la iconografía masculina.

«Pero la venda no siempre estuvo allí», recordó la Corte Constitucional colombiana en la sentencia SU-796 de 20I4, a propósito de la simbología de la justicia cegada:

En un comienzo, incluso, esta era asumida negativamente como una profunda limitación para cualquier persona así agobiada con la falta de visión. En un grabado atribuido a Durero y que ilustra la obra de Sebastián Brant de I494, «La nave de los necios», aparece uno de los necios (que siempre visten sombreros con orejas de asno) poniéndole la venda a la justicia y, por ende, induciéndola al error y a la estulticia.

Es probable que el imaginario común de la justicia de ojos vendados, como aquél frío e impávido funcionario que se limita a esperar que las partes dispongan sus pretensiones sobre la balanza, no represente a cabalidad el ideal del juez dentro del Estado social y democrático de derecho.

Justamente estar con los ojos bien abiertos, observar a cada una de las partes situadas en sus diferencias, comprender las formas de opresión y privilegios que subyacen en sus interrelaciones, podría ser lo más conveniente para un juez que siendo imparcial, no por ello sea indiferente a la realidad. La intuición de la edad media, transmitida a nosotros por el gran escultor y grabador Durero, es que la ceguera puede perpetuar la injusticia en el escenario judicial, situación aún más intolerable en un estado que se declara social de derecho, ergo, comprometido con la dignidad humana y la igualdad material de sus coasociados, nos dice la Corte.

La discriminación, entendida como el trato desigual no justificado, frecuentemente ensañada en factores como raza, género y clase, demandarían una reconfiguración del concepto de igualdad. En ciertas situaciones, estos factores deben no solamente ser observados, sino que además exigen una actuación del Estado para promover la igualdad en un marco de desigualdad histórica. Así, a la igualdad ante la ley se sumará la igualdad en la ley, tal como lo recoge el art. I3 superior, al establecer la cláusula de prohibición a la discriminación y los sujetos de especial protección.

Este principio/derecho de igualdad posee un alto contenido sustancial, material, un mandato que pretende remover un pasado de exclusión social en amplios sectores poblacionales. Irradiados por él han crecido, siguiendo a Nancy Fraser, políticas de inclusión mediante el reconocimiento, la representación y la redistribución? ${ }^{7}$ Desde esta

\footnotetext{
${ }^{7}$ FraSer, Nancy, Las escalas de la justicia. Pensamiento Herder dirigida por Manuel Cruz, Barcelona, 2008.
} 
triada se pretende que, mediante el impulso de leyes y políticas públicas del orden nacional y local, se promueva que los colectivos o grupos minoritarios alcancen un mayor reconocimiento -empoderamiento- mediante el respeto y la dignidad de su diferencia. Persiguen también que mediante acciones afirmativas se permita la representación política adecuada y suficiente de mujeres, indígenas y afros, así como proveer condiciones materiales que les permitan disfrutar de los derechos en similar manera que los demás, superando la pobreza y precariedad económica a través de políticas redistributivas. Éstas mejor formuladas en los estados del bienestar con medidas universales que previenen los condicionamientos en las prestaciones sociales. Por el contrario, en nuestro contexto la reetnización y el consecuente fraude, incentiva la focalización.

A los grandes esfuerzos legislativos por positivizar las conductas que vulneran los derechos de las mujeres y promover su investigación y sanción (leyes I257/I7I9/I76I) se resiste la escalofriante cifra de un $98 \%$ de impunidad para estos delitos ${ }^{8}$. La pregunta es entonces ¿dónde se encuentra el verdadero obstáculo a la igualdad en el género? La respuesta parece ubicarse en la cultura patriarcal y los estereotipos que suelen asignarse a los roles de género.

\section{Debido proceso con enfoque de género}

Como herramienta analítica de reciente creación en las ciencias sociales, el género fue introducido por Robert Stoller (I985) a raíz de los estudios psicológicos de la identidad personal, en la búsqueda de diferenciación entre la biología y la cultura. A mediados del siglo XX, Simone de Beauvoir al formular en su célebre obra El segundo sexo que «no se nace mujer, llega uno a serlo, ningún destino biológico, físico o económico define la figura

\footnotetext{
${ }^{8}$ Son múltiples los factores que pueden contribuir al altísimo nivel de impunidad reconocido en el país. Tres son los aspectos identificados: i) la batalla de las cifras, ii) las características del contexto familiar de la violencia y la vulnerabilidad de sus víctimas y iii) las deficientes prácticas de los cuerpos de investigación y judicialización. En primer lugar cabe mencionar la importancia de los datos. De hecho, la regla general es la inconsistencia de los datos producto de la heterogeneidad en las formas de recolección y medición de los mismos por las instituciones (la falta de interoperatividad o capacidad de interlocutar entre ellos), sumado a la falta de armonización conceptual y metodológica entre los agentes receptores de denuncias; así como de los prestadores de servicios en la ruta de atención en los casos de violencias contra las mujeres, aspectos que contribuyen a agravar la ya de por sí difícil tarea de analizar, visibilizar y difundir con certeza la magnitud del fenómeno. Pese a la batalla estadística, los datos son sumamente elocuentes con relación al segundo elemento del contexto familiar de la violencia y el ensañamiento con los NNA « (...) se puede observar una tendencia estable entre 2007 y $2016-2017$ en el que entre el $80 \%$ y $85 \%$ de las víctimas de violencia sexual son mujeres, es decir que la relación puede llegar a ser de 5 mujeres víctimas por I hombre víctima. Los grupos de edad más afectados para las mujeres es el de las niñas que tienen entre ıo y I4 años; y para los niños son los que tienen entre 5 y 9 años. Así mismo, las diferentes intervenciones presentaron que el agresor, normalmente, es una persona cercana a la víctima (familiares: padre o padrastro, tío o primo, etc. Conocidos o amigos de la familia, la pareja o expareja de su madre). Vale la pena resaltar, también, que $65 \%$ de los hechos ocurren en la casa/hogar donde se aprovechan situaciones en las que hay ausencia de la madre o el padre. Cerca del $40 \%$ de las niñas que quedaron embarazadas y fueron sujeto de agresión sexual no recibieron la suficiente orientación sobre la interrupción voluntaria del embarazo». Sobre el tercer elemento, las pocas denuncias derivan del aspecto anterior «teniendo en cuenta que, normalmente, el agresor es alguien cercano la denuncia es poco probable que se haga porque se convierte en un tema que se oculta en la familia. De hecho, en el país solo el $20 \%$ de las víctimas denuncian. Se destaca entre los principales motivos para no denunciar que el daño sea considerado como poco significativo y se naturaliza como un hecho de la vida, que es algo que puede resolverse/manejarse en privado, se tiene miedo a la retaliación, no se sabe a dónde ir, no quieren herir al agresor, no se denuncia para no sentir vergüenza». Con relación al funcionamiento del aparato judicial, tan solo el $20 \%$ de las denuncias se concretan 0 materializan en una captura. Relatoría Fundación Plan, Evento «Por una respuesta judicial Adecuada», organizado por el Consejo de Estado el 23 de noviembre del or7 en Bogotá D.C.
} 
que reviste en el seno de la sociedad la hembra humana», permitió entender que «mujer» no era una identidad natural sino una identidad y un proyecto culturalmente interpretado, dando lugar a la segunda ola feminista9. Ésta va más allá de la lucha por la igualdad de derechos políticos. De esta premisa se desprendería, con fundamento en los estudios de la prominente antropóloga estadounidense Margaret Mead, que el temperamento o personalidad está determinado culturalmente y no biológicamente, y que la mayor parte de las sociedades divide en dos categorías binarias los rasgos humanos de carácter, los especializa para constituir las actitudes y las conductas apropiadas para cada uno de los $\operatorname{sexos}^{\mathrm{ro}}$. Lo cual, con los estudios feministas posteriores, se entendería como una forma arbitraria de imponer los roles, estereotipos sexuales, la división sexual del trabajo, la jerarquía y desigualdad entre hombres y mujeres y, por ende, da lugar a la opresión y subordinación de las mujeres ${ }^{\mathrm{II}}$.

${ }^{9}$ La primera ola feminista sería impulsada por Olympe de Gouges, el marqués de Condorcet, Etta Palm, Théroigne de Méricourt y el Cercle Social que exigían el voto de las mujeres, la disponibilidad del divorcio y la abolición de las leyes de herencia que favorecían al hijo varón primogénito en el periodo de la revolución francesa. Esta última solicitud fue rápidamente aceptada por la Asamblea el i5 de marzo de I790 por contribuir a acabar el poder de los grandes patriarcas nobles, más que por reforzar las libertades económicas de las mujeres. Al año siguiente, I79I, Olympe publicó un proyecto de contrato social para acuerdos matrimoniales relativo a los hijos y a la propiedad, y la Declaración de los Derechos de las Mujeres y de los Ciudadanos, como respuesta a la ausencia de las mujeres en la Declaración de los derechos de los hombres y los ciudadanos, quién vale la pena señalar, al igual que Méricourt, no fueron hostigadas por feministas, sino por girondinas. De hecho, los grandes progresos en los derechos de las mujeres y los niños se llevarían a cabo con la Constitución jacobina de I793 con medidas como: i) entregar al estado la responsabilidad de los niños huérfanos o abandonados; ii) garantizar los plenos derechos de herencia a los niños nacidos por fuera del matrimonio (algo que Colombia aprobaría en I984, I9I años después!); iii) la ley del divorcio votada en la última sesión de la Asamblea Legislativa el 20 de septiembre de 1792 que permitía la disolución de un matrimonio infeliz mediante el mutuo acuerdo por incompatibilidad, por la prolongada ausencia de su pareja o por crueldad; iv) Se establecieron tribunales de familia para resolver la violencia doméstica introduciendo multas el doble de severas que las que se imponían por asaltar a un hombre. Sobre la vigorosidad en la aplicación de la ley narra Mc Phee: «las mujeres trabajadoras fueron quienes más se sirvieron de esta ley: en Ruán, por ejemplo, el 7I por ciento de los pleitos de divorcio fueron iniciados por mujeres, y el 72 por ciento de los mismos procedían de mujeres del ramo textil con cierta independencia económica, a diferencia de la mayoría de las mujeres del campo. En el ámbito nacional, se decretaron unos 30.000 divorcios bajo esta ley, especialmente en las ciudades: en París hubo casi 6.000 en el periodo I793-I795». La brecha entre la lucha por los derechos de las mujeres desde el ala conservadora y la lucha por la igualdad social de los jacobinos serían conciliadas por las Ciudadanas Republicanas Revolucionarias bajo el liderazgo de Claire Lacombe y Pauline Léon, quienes reclamarían los derechos de las mujeres a acceder a cargos públicos, a portar armas y la sororidad. Propuesta que a la postre sería pasajera por cuanto su capacidad de convocatoria para integrar la sociedad se encontraría con la oposición de algunos líderes jacobinos y de las mujeres del mercado para quienes las medidas de control de precios las amenazaba con la pobreza, llegando a apalear a un grupo de Ciudadanas, lo que ofreció a la Convención y algunos jacobinos como Amar, del Comité de Seguridad de la Convención la oportunidad de tomar partido en su contra. «El 30 de octubre todos los clubes femeninos, incluyendo sesenta de las zonas provinciales, fueron clausurados». Mc PHEE, pp. I67-I7I. Sobre los malentendidos con relación a Olympe ver el indispensable texto de Florence Gauthier, «Olympe de Gouges: ¿historia o mistificación? », en Sin permiso, República y Socialismo también para el S. XXI; edición de I6/03/20I4, http://www.sinpermiso.info/textos/olympe-de-gouges-historia-o-mistificacin, página revisada el 20/04/I7.

La segunda mujer sería Mery Wollstonecraft en Inglaterra con su obra A vindication of the rigths of woman y el movimiento de las sufragistas que reclamaban igualdad de derechos civiles y políticos a los entregados a los hombres tras las grandes revoluciones del s. XVIII.

${ }^{\text {ro }}$ Sin duda uno de los principales méritos de Mead fue el de darle voz a las mujeres al realizar una de las primeras etnografías con informantes femeninas, las cuales solían ser invisibilizadas por los antropólogos que únicamente consideraban como sus informantes a los hombres. Para profundizar en los grandes aportes a la antropología y a las ciencias sociales de Mead y otras antropólogas feministas consultar MARTín CASARES, Aurelia, Antropología del género, Culturas, mitos y estereotipos sexuales. Cátedra, Universitat de Valencia, Instituto de la Mujer, Valencia, 2008.

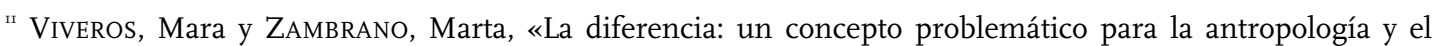
feminismo», en: El género: una categoría útil para las ciencias sociales. Luz Gabriela Arango Gaviria, Mara Viveros Vigoya (Editoras). Colección Estudios de Género, Facultad de Ciencias Humanas, Universidad Nacional de Colombia, 20I3, pp. I43-I70. También consultar SCOTT, Joan, «El género: una categoría útil para el análisis histórico», en: El género: la construcción cultural de la diferencia sexual. Lamas Marta, Compiladora. PUEG, 
Como última medida, con la llegada de la tercera ola, el género como principio ordenador se conjugará con otros sistemas de dominación, jerarquía y subordinación como la clase, la etnicidad, la «raza» y la orientación sexual, entrando a cuestionar la premisa de partida de la política feminista, es decir, la existencia real o potencial de una identidad común de «mujer»: la sororidad como supuesta hermandad que oculta la condición hegemónica, heteronormativa, blanca e ilustrada de ese feminismo. En suma, se transita de un feminismo de la igualdad a un feminismo de las diferencias, de las mujeres y sus intersecciones, que visibiliza el lugar que ocupa la raza (black feminist), la hegemonía cultural (las críticas postcoloniales ${ }^{12} y$ decoloniales $^{13}$ ) y la orientación sexual (teorías queer) como relaciones de poder estructurantes de las ilaciones de género y de la opresión patriarcal.

Así las cosas, en el ámbito del derecho, el enfoque de género es una categoría de análisis que permite evidenciar cómo los valores, actitudes y normas que conforman los géneros obedecen a una construcción social y no biológica -no determinada por el sexo de nacimiento- que repercute en los comportamientos e imaginarios adscritos a una sociedad patriarcal, en la que las formas binarias hombres/mujeres, masculino/femenino, se encuentran en desigualdad e inequidad. Por su parte, en la construcción social del sexo, se asignan estereotipos, entendidos como un conjunto de ideas, prejuicios, generalizaciones, simplificaciones, positivas o negativas, que se atribuyen al otro, individual o colectivo, aún desconocido.

El estereotipo fue definido por G. Allport (I954) como una creencia exagerada asociada con, o acerca de, las costumbres y atributos de un determinado grupo o categoría social; una creencia exagerada cuya función es la de justificar o racionalizar nuestra conducta en relación con dicha categoría de gente.

¿Cómo y por qué se produce esa creencia, esa exageración distorsionada? La generación de estereotipos obedece tanto a la necesidad o el deseo de tener alguna opinión sobre los demás, como a la dificultad de, o falta de interés en, fundar esa opinión en la experiencia propia y suficiente de la que derive un conocimiento directo y sólido.

En su forma más corriente los estereotipos, positivos o negativos juegan un papel primordial en nuestras relaciones sociales y personales con desconocidos al ayudarnos a adjudicar a los otros «un papel» o rol en el juego de estas relaciones. Este papel es adjudicado no en función de los logros personales de nuestro interlocutor, si no en función del estereotipo que tenemos del grupo al que adscribimos a dicho individuo. ${ }^{\mathrm{T}}$

México, pp. 265-302.

${ }^{12}$ Sobre la crítica del feminismo del tercer mundo a la colonialidad discursiva del feminismo occidental hegemónico, MoHANTY, Chandra, «Bajo los ojos de occidente. Academia Feminista y discurso colonial», en: Descolonizando el Feminismo: Teorías y Prácticas desde los Márgenes. Liliana Suárez Navaz y Aída Hernández (editoras). Cátedra, Madrid, 2008.

${ }^{13}$ Sobre las diferencias entre el feminismo postcolonial y decolonial latinoamericano, CuRIEL PICHARDo, Ochy, «Construyendo metodologías feministas desde el feminismo decolonial», en Otras formas de (Re)conocer, Reflexiones, herramientas y aplicaciones desde la investigación feminista. Irantzu Mendia Azkue, Marta Luxán, Matxalen Legarreta, Gloria Guzmán, Iker Zirion, Jokin Azpiazu Carballo (eds.), Universidad del País Vasco, Donostia-San Sebastián, 20I4.

${ }^{14}$ MALGesini, Graciela y GiménEZ, Carlos, Guía de conceptos sobre migraciones, racismo e interculturalidad, Catarata, Madrid, 2000, pp. I47-I48. 
Desde los estereotipos se imparten normas de conducta mediante instrucciones transmitidas por la familia, la escuela, la publicidad, el cine, la música, la ley, sobre cómo deben comportarse los hombres y las mujeres. Son imperativos culturales que cuando son individualmente transgredidos provocan el rechazo del grupo mediante el oprobio, la burla, el aislamiento $\mathrm{u}$ ostracismo, los denominados controles sociales, y/o la violencia en cualquiera de sus formas -bullying, maltrato, abuso, inducción al suicidio, etc.-, es decir, prácticas discriminatorias.

Los estereotipos aparentemente inocentes sobre el tamaño, talla, modales, vestuario, maquillaje, estándares de bella, condicionan el cuerpo y el performance de ser mujer, al igual que el tono de la voz, la contextura física, estatura, corte de cabello, fuerza y capacidad económica, el performance de ser hombre, desde el molde cultural y normativo bastante estrecho de la identidad de género, reforzando una relación binaria que excluye el tercer sexo, la intersexualidad, los tránsitos. Particularmente en la construcción de la identidad masculina, el varón es forzado a reprimir aquellos aspectos considerados femeninos o feminizantes, «el potencial del sujeto para la bisexualidad», según Joan Scott ${ }^{15}$, e introduce el conflicto en la oposición de lo masculino y femenino, en donde la expresión de las emociones y sentimientos como el dolor, el afecto, el miedo son asociados con la debilidad y, por ende, el principal aspecto a ocultar y a sancionar cuando son exhibidos.

Los roles suelen ser atesorados y reproducidos por las prácticas familiares y sociales que sancionan con violencia la transgresión que frente a estos se busque realizar por ciertos individuos que muestran resistencias a las restricciones a la libertad que tales asignaciones conllevan.

El efecto de dicha violencia sobre la integridad física y mental de las mujeres es que las priva del goce efectivo, el ejercicio y aun el conocimiento de sus derechos humanos y libertades fundamentales, con consecuencias que contribuyen a mantener a la mujer subordinada mediante su escasa participación en política, su nivel inferior de educación y capacitación, así como en la limitada posibilidad de obtener oportunidades de empleo de calidad.

Así las cosas, el enfoque de género pone en evidencia las situaciones de discriminación y desigualdad que aquejan a las mujeres, así como los estereotipos e imaginarios que a través de la cultura influyen en la percepción de los roles a desempeñar por los géneros. En el proceso judicial, la cultura patriarcal también se encuentra presente en la legislación y en la interpretación del derecho, permeando la valoración de las pruebas y la facultad del juez o jueza para llegar a la formación del libre convencimiento, por lo cual mediante el debido proceso con enfoque de género se busca garantizar una decisión judicial que no de eco a los prejuicios sociales y culturales, y que por el contrario contribuya a la superación de los patrones de discriminación hacia las mujeres ${ }^{16}$.

Pese a los grandes avances normativos y jurisprudenciales a nivel internacional, en la práctica, los servidores públicos, los y las jueces, suelen actuar en forma pasiva e

\footnotetext{
${ }^{15}$ SCOTT, Joan, «El género una categoría útil», en El género: la construcción cultural de la diferencia sexual. Lamas Marta (compiladora). PUEG, Méjico, pp. 265-302.

${ }^{16}$ Sobre el inconmensurable impacto de los estereotipos de género en la justicia y en las decisiones judiciales a lo largo y ancho del planeta, CooK, Rebecca y CusAck, Simone, Estereotipos de género. Perspectivas legales transnacionales. Traducción de Andrea Parra, Profamilia, Bogotá, 2009.
} 
indiferente ante el dolor femenino, atrapados en tres dinámicas: i) el formalismo, o si se quiere, acartonamiento probatorio que les induce a abstenerse de penetrar en lo considerado «privado» o «intimo», lugar en el que suelen darse las violencias de género; ii) el uso de un material probatorio inadecuado o improcedente para probar la violencia contra las mujeres, en desmedro de una amplia fuente de documentación y pruebas que establecen perfiles psiquiátricos del agresor, nivel de riesgo de las víctimas, sistematicidad de la conducta; y ii) los pactos secretos.

i. De la primera dinámica se deriva una sistemática impunidad o tolerancia generalizada a la violencia, en tanto se omite el deber de la debida diligencia. En este contexto, los y las servidores públicos, funcionarias judiciales y de policía están equipados con cientos de excusas para evitar y/o soslayar iniciar y culminar con éxito las investigaciones que envuelven situaciones de vulneración de los derechos de las mujeres, frases como: «¿y dónde está la norma que me autoriza expresamente para actuar?, ¡mientras no haya sentencia condenatoria, no podemos hacer nada!, ¡si ella se defendió es que fueron agresiones mutuas! $\gg^{\text {17}}$, son de uso frecuente en los lugares de recepción de las denuncias y/o, despachos administrativos y organismos de policía. Prácticas que configuran una forma de violencia institucional que agrava la situación de las victimas generando una revictimización proscrita por el derecho internacional y nacional ${ }^{18}$.

ii. El uso de material probatorio inadecuado para probar las violencias contra las mujeres y NNA o, la no valoración del acervo probatorio que reposa en el expediente y que demuestra la vulneración de los derechos son prácticas que tienen una directa relación con el uso tradicional del derecho en el que las pruebas dominantes son los testimonios y los documentos. En efecto, la mayor parte de los procesos judiciales son resueltos con este conjunto de pruebas, de fuerte presencia en la investigación y condena en la comisión de las contravenciones y delitos.

No obstante, cuando de lo que se trata es de investigar lo sucedido en el interior de un hogar, ninguna de estas pruebas suele tener repercusión. En los testimonios, por cuanto no hay observadores de lo sucedido o éstos son NNA hijos de la pareja, cuya versión de los hechos es silenciada, no creída, invalidada o cuestionada ${ }^{\text {I9 }}$. Por su parte, las pruebas documentales no están presentes o arrastran las falencias del

${ }^{17}$ Esta expresión esconde una suerte de esencialización que responde a la construcción de un imaginario de «la víctima perfecta»: la persona débil, desprotegida, frágil física y psicológicamente que recibe toda clase de maltratos y se encuentra desprovista de cualquier posibilidad de reacción y defensa.

${ }^{18}$ La Corte Constitucional ha interpretado el principio de la debida diligencia en el sentido que las autoridades encargadas de prevenir y erradicar toda forma de violencia contra la mujer, evalúen los testimonios de las víctimas a la luz de un enfoque de género, evitando toda revictimización. Corte Constitucional, sentencia T-027 de 20I7. M.P. Aquiles Arrieta.

ז9 Más aún con el uso judicial de una herramienta aparentemente técnica, que bajo un falso manto de neutralidad pone en cuestión la versión de los NNA como es el SAP el falso -Síndrome de Alienación Parental-, inventado por el siquiatra Richard Garner y solicitado generalmente por los padres para acusar de manipulada por la madre la versión de los niños, niñas y adolescentes en los casos de incesto y violencia sexual en el entorno familiar. Mediante esta estrategia «(...) Ya el ofensor sexual no es el victimario, sino la víctima, y el niño no es la victima sino el verdugo de su propio padre o victimario. », CUADROS FERRÉ, Isabel, «Introducción, ¿Por qué no vemos la violencia contra los niños? », en Evaluación médica del abuso sexual infantil, Una guía práctica. Martin A. Finkel y Angelo P. Giardino; American Academy of Pediatrics, 2009. Traducción autorizada de la Asociación Afecto contra el maltrato infantil, Bogotá, D.C., 20I5, p. 23. 
sistema judicial, como es que se trata de procesos judiciales iniciados por la mujer contra su pareja pero que no llegaron a ningún puerto; órdenes de alejamiento que fueron incumplidas y sin consecuencias; o informes físicos, psiquiátricos de medicina legal que dan cuenta del perfil del victimario y del tipo de riesgo que representa, pero que lamentablemente suelen ser apartados de la toma de decisión, y que de conformidad a la jurisprudencia constitucional constituyen un error fáctico como causal de procedibilidad de la acción de tutela contra decisiones judiciales ${ }^{20}$. En este ámbito es donde el debido proceso con enfoque de género ha tomado más contundencia en la jurisprudencia constitucional nacional.

iii. Los pactos secretos, considero que son un fenómeno arraigado en la sociedad, tácito e incómodo, que empuja a ciertas personas a empatizar con la versión del victimario y sus condiciones, únicamente porque resulta menos perturbador, inquietante, transgresor, que creer en la versión de la víctima (llámese niña, niño, adolescente, mujer o hombre), en especial cuando ello supone confrontar instituciones como la escuela, el ejército, la religión. Es decir, cuando se pone en cuestión los referentes fuertes de la identidad: las creencias, la autoridad, la familia o las bases de la sociedad en las que cada uno se soporta. Si bien en el ámbito judicial se ha identificado el fenómeno como empatía con el victimario ${ }^{2 \mathrm{I}}$, pienso que el concepto de «pactos secretos» recoge en mejor medida lo vergonzoso y oculto de esta clase de prácticas que además surgen en forma generalmente inconsciente y espontánea, si se quiere naíf, pero que contribuye, de un lado, a gestar y mantener la impunidad, y de otro, a alimentar la excesiva autoconfianza de ciertos victimarios. ¿Qué factores del consiente y subconsciente operan en estos comportamientos?, ¿por qué algunas personas son más solidarias con los fuertes que con los débiles? Son preguntas sobre las que aún hay mucho por resolver. ${ }^{22}$

Previamente hemos señalado que la discriminación puede ser entendida como todo trato desigual no justificado. Cuando se refiere a las mujeres, de conformidad a la Convención sobre la eliminación de todas las formas de discriminación contra la mujer -

${ }^{20}$ En palabras de la Corte «Este defecto se caracteriza cuando el juez toma una decisión sin que las circunstancias fácticas del caso se subsuman adecuadamente en el supuesto de hecho que legalmente la determina, como consecuencia de una omisión en el decreto o valoración de las pruebas; de una apreciación irrazonable de las mismas; de la suposición de una prueba; o del otorgamiento de un alcance contraevidente a los medios probatorios. Es decir, existen en la providencia cuestionada fallas sustanciales, atribuibles a deficiencias probatorias dentro del proceso». Corte Constitucional sentencias T-587/17, T-902 de 2005 M.P. Marco Gerardo Monroy Cabra. La doctrina ha además distinguido entre defectos facticos en dos dimensiones: positiva y negativa, al respecto consultar QUINCHE R., Manuel Fernando, Vías de hecho. Acción de tutela contra providencias. Ed. Ibáñez y Pontificia Universidad Javeriana, 20I2, p. I88.

${ }^{21}$ En la conferencia de Nydia Cerinza, Magistrada auxiliar del despacho de la Magistrada Stella Conto, titulada «Estudio de casos» en el Evento «Por una respuesta judicial Adecuada», organizado por el Consejo de Estado el 23 de Noviembre del 2017 en Bogotá D.C.

${ }^{22}$ Un extremo de este «pacto secreto» ocurrió con relación a los sacerdotes pederastas católicos y la sorprende facilidad con la que podían embaucar a las familias católicas, llenas de fe, abusando sexualmente de sus hijos sin apenas generar reacciones en la comunidad. Un sacerdote violador explica esta incapacidad para ver lo que está sucediendo «porque la gente quiere creer en algo. Ellos quieren esperanza, quieren creer. Ellos quieren... hay algo dentro de la gente que les hace querer creer en los mejor de las cosas y de los otros. Porque la alternativa no es muy agradable. Suficiente verdad. La alternativa no es muy agradable». SALTER, Anna C., Predators, pedophiles, rapists, Q other sex offenders: who they are, how they operate, and how we can protect ourselves and our children. Basic Books, New York, 2003, p. 29. Traducción propia. 
CEDAW- ${ }^{23}$, se define como «toda distinción, exclusión o restricción basada en el sexo que tenga por objeto o por resultado menoscabar o anular el reconocimiento, goce o ejercicio por la mujer, independientemente de su estado civil, sobre la base de la igualdad del hombre y la mujer, de los derechos humanos y las libertades fundamentales en las esferas política, económica, social, cultural y civil o en cualquier otra esfera». En el ámbito interamericano, la Convención Belém do Pará $^{24}$ señala que la violencia contra la mujer es «una manifestación de las relaciones de poder históricamente desiguales entre mujeres y hombres» y reconoce que el derecho de toda mujer a una vida libre de violencia incluye el derecho a ser libre de toda forma de discriminación.

Con la misma orientación, el Comité de la CEDAW ha declarado que la definición de la discriminación contra la mujer «incluye la violencia basada en el sexo, es decir, la violencia dirigida contra la mujer [i] porque es mujer o [ii] que la afecta en forma desproporcionada». Incluye actos que infligen daños o sufrimientos de índole física, mental o sexual, amenazas de cometer esos actos, coacción y otras formas de privación de la libertad. La violencia contra la mujer puede contravenir disposiciones de la Convención sin tener en cuenta si hablan expresamente de la violencia. Dentro de la categoría de violencia basada en el sexo, el Comité incluye violencia por «acto privado» y «violencia en la familia». Por consiguiente, la violencia basada en el sexo comporta obligaciones para los Estados.

También la CIDH, al resolver el caso conocido como campo algodonero, del feminicidio en ciudad Juárez, tuvo la oportunidad de analizar la cultura de la discriminación contra la mujer la cual se funda «en una concepción errónea de su inferioridad» que afecta el proceso penal al producir inacción (discriminación en el acceso a la justicia al descalificar la credibilidad de la víctima), empequeñecer las investigaciones que involucran los derechos de las mujeres (impunidad) y postergar las acciones inmediatas y contundentes por parte de las autoridades competentes (actuación reproductora de la violencia que se busca atacar). «Esta influencia también puede afectar en forma negativa la investigación de los casos y la valoración de la prueba subsiguiente, que puede verse marcada por nociones estereotipadas sobre cuál debe ser el comportamiento de las mujeres en sus relaciones interpersonales». ${ }^{25}$

Según la CIDH, los comentarios efectuados por funcionarios en el sentido de que las víctimas se habrían ido con su novio o que tendrían una vida reprochable y la utilización de preguntas en torno a sus preferencias sexuales constituyen estereotipos.

Con una mirada más cercana a la interseccionalidad, la Comisión también ha reconocido que ciertos grupos de mujeres padecen discriminación en base a más de un factor a lo largo de su vida, en virtud de su corta edad, su raza y su origen étnico, entre otros, lo que aumenta su riesgo de sufrir actos de violencia. Las medidas de protección se consideran particularmente críticas en el caso de las niñas, por ejemplo, dado que pueden estar expuestas a mayores riesgos de violación de sus derechos humanos en razón de dos

\footnotetext{
${ }^{23}$ Ratificada mediante la Ley 5I de I98I.

${ }^{24}$ Ratificada mediante la Ley 248 de I995.

${ }^{25}$ Caso González y otras («Campo Algodonero») vs. México. Excepción Preliminar, Fondo, Reparaciones y Costas. Sentencia de I6 de noviembre de 2009. Serie C No. 205.
} 
factores: su sexo y su edad. Este principio de protección especial está consagrado en el artículo VII de la Declaración Americana.

Por su parte, la CIDH al estudiar el caso del Penal Castro Castro vs. Perúc ${ }^{26}$, señaló que cuando las mujeres se encuentran detenidas o arrestadas «no deben sufrir discriminación, y deben ser protegidas de todas las formas de violencia o explotación». Con esta finalidad, analizó distintas privaciones en el ámbito carcelario que si bien se establecen para todos los reclusos, recaen en forma desproporcionada sobre las mujeres por su condición y necesidades propias del embarazo, la maternidad o por el simple hecho de ser mujeres: como, por ejemplo, la falta de suministro en toallas higiénicas, la exigencia de que «deban ser supervisadas y revisadas por oficiales femeninas», o que las mujeres embarazadas y en lactancia «deben ser proveídas con condiciones especiales».

Ante las grandes barreras en el acceso a la justicia que deben sortear las mujeres, el derecho internacional ha buscado principalmente remover la pasividad de la rama judicial y los estereotipos opresivos que limitan la actuación judicial en el proceso judicial, mediante los siguientes principios: I) la debida diligencia; 2) garantía de un recurso efectivo; 3) la obligación de investigar; 4) obligación de juzgar, castigar y reparar.

\section{III.I. El Principio de debida diligencia}

La debida diligencia, en tanto principio y derecho, ha sido interpretada como la obligación de los Estados de recurrir a «todos los medios legales, políticos, administrativos y culturales para promover la protección de los derechos humanos y asegurar que toda violación sea considerada y tratada como un acto ilícito que puede dar lugar al castigo de los responsables y la obligación de indemnizar a las víctimas». Es decir, los Estados Parte están obligados a suministrar recursos judiciales efectivos para prevenir, investigar, sancionar y reparar los actos de violencia contra la mujer, que deben ser sustanciados de conformidad con las reglas del debido proceso legal (artículo 8.I), todo ello dentro de la obligación general de garantizar el libre y pleno ejercicio de los derechos reconocidos por la Convención a toda persona que se encuentre bajo su jurisdicción (artículo I.I).

Son parte de la debida diligencia la investigación en contexto, en el sentido de que debe tomarse en cuenta lo ocurrido en otras vulneraciones de derechos $u$ homicidios y establecer algún tipo de relación entre ellos. En este sentido, la CIDH, al analizar el caso del campo algodonero del feminicidio de ciudad Juárez, estableció que los estados, al adelantar líneas de investigación separadas para casos en concreto -estrategia que puede llegar a ser eficaz- no deben dejar de lado que éstas se enmarquen en un contexto de violencia contra la mujer. Actuación que debe ser impulsada de oficio, sin que sean las víctimas y sus familiares quienes tengan la carga de asumir tal iniciativa.

Con relación al vínculo entre la discriminación, como una forma de violencia contra la mujer y la debida diligencia, es deber de los Estados emprender las medidas educativas y

\footnotetext{
${ }^{26}$ Después de esta decisión, la Corte Interamericana profundizará sobre el concepto y alcance del enfoque interseccional en las sentencias Caso Gonzales Lluy y otros vs. Ecuador*, de I de septiembre de 2015 (excepciones preliminares, fondo, reparaciones y costas) y Caso i.v.* vs. Bolivia sentencia de 30 de noviembre de 2016 (excepciones preliminares, fondo, reparaciones y costas).
} 
pedagógicas necesarias para modificar los patrones de comportamiento sociales y culturales de hombres y mujeres, y eliminar los prejuicios y las prácticas consuetudinarias basadas en la premisa de la inferioridad o superioridad de uno de los sexos, y sobre los roles estereotipados que se les imponen.

Estos principios también han sido aplicados para responsabilizar a los Estados por fallas en la protección de las mujeres respecto de actos de violencia doméstica cometidos por particulares. En esta línea, se ha reconocido internacionalmente que la violencia doméstica es una violación de los derechos humanos y una de las formas más persistentes de discriminación, que afecta a mujeres de todas las edades, etnias, razas y clases sociales ${ }^{27}$.

Por último, el principio de la debida diligencia le exige a los y las jueces el deber de documentar integralmente los hechos yendo más allá del sistema probatorio tradicional en atención a que la mayoría de las veces el maltrato en todas sus formas sucede en el ámbito privado de la familia, en donde, como ya se ha mencionado, los testigos y pruebas documentales que protocolizan las relaciones entre terceros no suelen estar presentes ${ }^{28}$. Siendo pertinente acudir a estadísticas, protocolos de atención, informes, estudios de situación, centros de pensamiento de género, jurisprudencia, que permitan probar la sistematicidad o generalidad de la conducta ${ }^{29}$.

III.2. La garantía de un recurso judicial efectivo

El derecho a un recurso efectivo ha sido contemplado en múltiples instrumentos internacionales, implica la capacidad de poder reivindicar los derechos ante un órgano independiente e imparcial, con el fin de obtener reconocimiento de la violación, el cese de la violación si ésta continúa, y una adecuada reparación ${ }^{30}$. Lo cual excluye la justicia penal

\footnotetext{
${ }^{27}$ Respecto a la violencia doméstica ver el precedente interamericano que constituye el Informe No. 54/OI, Caso I2.05I, Caso Maria da Penha vs. Brasil.

${ }^{28}$ En este sentido es importante resaltar el caso emblemático que constituye la sentencia T-967 de 20I4, bajo ponencia de la magistrada Gloria Ortiz, en el que la Corte tuvo la oportunidad de pronunciarse en torno al análisis probatorio para determinar la violencia sicológica en el ámbito doméstico, para lo cual estableció un precedente con relación a la administración de justicia con perspectiva de género. Esto último entendido como un llamado a que los funcionarios judiciales desplieguen una mayor creatividad probatoria para derrumbar los muros que se elevan en el espacio de lo íntimo, y para permitirse una mayor sensibilidad sin la excusa de la imparcialidad como arma para mantener el estatus quo de impunidad frente a estos delitos. En este caso, una mujer, fiscal, impetra la acción de tutela contra la sentencia del juzgado $4 \mathrm{ffl}$ de familia de Bogotá que negó el divorcio por la causal 3 ffi, correspondiente a «ultrajes, el trato cruel y los maltratamientos de obra», en los cuales se ubica el maltrato sicológico, básicamente porque: i) la mujer había construido las pruebas; ii) no encontró probados hechos de violencia o agresiones al interior del hogar.
}

En los hechos de la demanda se narran los empujones, cachetadas, revisiones en su ropa, insultos, acusaciones de infidelidad con cualquier persona que se cruzara en el camino o la vida de la víctima -incluyendo al fiscal y Vicefiscal general de la nación-, ultrajes a los que era sometida constantemente la mujer tanto en su entorno familiar como laboral por parte de su esposo, hasta el punto de llegar a practicar una prueba de ADN en su hija por dudar de su paternidad. A pesar de que estos comportamientos se ubican en el diagnóstico de la celotipia, enfermedad mental que se traduce en una suerte de paranoia basada en el deseo compulsivo de poseer en exclusiva y en forma absoluta a la persona amada, y constituye uno de los detonantes más claros del maltrato en las parejas, la jueza de familia no pudo identificarlo. Por el contrario, el aislamiento social y familiar que ya había provocado el esposo sobre la mujer, la cual ni siquiera podía almorzar con sus compañeros de trabajo, fue utilizado para, en clara pasividad y pereza probatoria, blindar el maltrato con la forma más facilista, bajo el concepto de la intimidad y usando como herramienta la lectura más formalista del derecho al debido proceso.

${ }^{29}$ ArbeláeZ, Lucia; RuIZ, Esmeralda y otra, Criterios de equidad para una administración de justicia con perspectiva de género. Comisión Nacional de género. Consejo Superior de la Judicatura, Bogotá, Agosto 20 II.

${ }^{30}$ En términos similares consultar CIDH, Informe de Fondo, N 5/96, Raquel Martín de Mejía (Perú), I de 
militar para investigar, juzgar y sancionar casos que involucran violaciones de los derechos humanos.

Son múltiples las barreras de acceso a la justicia para las mujeres identificadas a nivel global ${ }^{3 \mathrm{I}}$. Éstas pueden verse agravadas en el país a raíz de la presencia de actores armados en los territorios, la distancia entre los puestos de salud, los costos del desplazamiento, la aún limitada descentralización del instituto nacional de medicina legal, la falta de despachos judiciales, la ausencia de formación en el enfoque de género y de sensibilidad por los servidores públicos y de los medios de comunicación, entre muchos más aspectos. Carencias todas ellas que deben ser superadas por los Estados dentro del deber de establecer garantías de no repetición ${ }^{32}$ y la lucha contra la impunidad en la violencia contra las mujeres. La jurisprudencia constitucional agregaría que además de reparación, la tutela judicial efectiva garantiza los derechos a la verdad y a la justicia ${ }^{33}$.

III.3. Obligación de investigar

La obligación de investigar se deriva de varios instrumentos internacionales ratificados por Colombia. La CoIDH ha determinado que de la obligación general de garantía se deriva la obligación de investigar los casos de violaciones de los derechos humanos.

En caso de graves violaciones, la investigación debe ser iniciada de oficio, esto es, independientemente de que las víctimas o sus familiares presenten una denuncia. Según los estándares internacionales en esta materia, la investigación debe ser inmediata, exhaustiva, seria e imparcial. Según la ley I76I/15 del feminicidio, la investigación debe ser además técnica, especializada, ágil, oportuna y efectiva.

En los casos de violencia contra las mujeres la investigación se constituye en una etapa crucial del procedimiento y por lo tanto no se puede subestimar la importancia de una debida investigación, ya que las fallas a ese respecto suelen impedir u obstaculizar ulteriores esfuerzos tendientes a identificar, procesar y castigar a los responsables. Por tanto, la investigación debe ser asumida por el Estado como un deber jurídico propio, que no debe depender de la iniciativa procesal de la víctima o de la aportación privada de elementos probatorios.

marzo de i996, p. 22.

${ }^{31}$ Recomendación General No. 33 de 15 de agosto de 2015 del Comité para eliminar la discriminación contra la Mujer de las Naciones Unidas, creado por La Convención sobre la eliminación de todas las formas de discriminación contra la mujer, CEDAW. En este documento se incluyen seis aspectos a fortalecer para superar las barreras de acceso a la justicia para las mujeres, como son: justiciabilidad, disponibilidad, accesibilidad, sistemas de justicia con calidad, rendición de cuentas de los sistemas y recursos. Un análisis sobre esta y otras recomendaciones del Comité se encuentran en la Sentencia T-24I de 20I6, Corte Constitucional.

${ }^{32}$ Caso campo algodonero, p. II5. (párr. 455).

${ }^{33}$ Esta doctrina fue desarrollada tanto en el ámbito de la justicia penal militar, como de la justicia penal ordinaria. Corte Constitucional, Sentencias C-293 de I995; C-I63 de 2000; C-II49 de 200I; C-228 de 2002; C805 de 2002; C-916 de 2002, C-454 de 2006, reiterada recientemente en la T-24I de 2016. 
Respecto de la obligación a cargo del Estado de llevar a cabo una investigación seria, inmediata, imparcial y exhaustiva es preciso reiterar que esta exigencia adquiere mayor relevancia cuando nos enfrentamos ante hechos de violencia contra las mujeres y que pueden ser constitutivos de crímenes de lesa humanidad o de guerra. En consecuencia, estaríamos ante una obligación reforzada en materia de investigación a cargo de las autoridades judiciales.

III.4. Obligación de juzgar, castigar y reparar

El juzgamiento de los responsables es una medida de prevención de futuros hechos de violencia. La imposición de sanciones penales permite enviar un mensaje a la comunidad en general de que este tipo de violencia no es tolerada por parte del Estado y que por el contrario la condena. De no ser así, la sistemática impunidad en que permanecen estos crímenes puede constituir un elemento importante que contribuye a la repetición de las violaciones.

Además se debe realizar una calificación de los delitos que evidencie el papel que desempeñó su comisión en el marco de la guerra, y de ser el caso la sistematicidad y generalidad con que fueron cometidos, para determinar si constituye un crimen de lesa humanidad. Adicionalmente tal obligación implica juzgar a todos los integrantes que pudieron estar involucrados en la comisión de los delitos, es decir no sólo a los autores directos sino a los máximos responsables.

A manera de síntesis y como conclusión preliminar, considero importante señalar que he escogido el concepto de debido proceso con enfoque de género porque desde él se irradia una completa armonía entre los conceptos, que en cambio difieren cuando se realiza en forma separada, consecutiva, o superpuesta. Lamentablemente cuando se disecciona el debido proceso y el enfoque de género las y los jueces pueden errar aun teniendo las mejores de las intenciones, dando interminables círculos sobre la espiral de los términos, el lenguaje apropiado, las normas, los protocolos, pero sin dejarse permear por la situación concreta, las vivencias de las mujeres o sus experiencias frente al derecho y su aplicación real. A esto quisiera llamarle «el género como retórica» y ocurre cuando los funcionarios, el aparato de investigación y el poder judicial parecen no lograr articular ambos conceptos en una sola noción abarcadora que resignifique la manera de recepcionar, impulsar, acompañar, tratar, investigar y fallar un asunto que envuelva la vulneración de los derechos de las mujeres y NNA. Así, nos podemos encontrar con decisiones judiciales que hagan un largo recuento positivo que enumere la normatividad internacional y nacional con relación al género, pero luego la olvide a la hora de resolver el caso concreto, pasando de largo sobre cómo en el asunto en ciernes justamente hubo practicas estereotipadas, barreras y obstáculos de acceso a la justicia, normalización de las violencias o reproducción de roles de subordinación en las mujeres. ${ }^{34}$

${ }^{34}$ Un ejemplo de lo enunciado es la sentencia T-24I-I6 sobre maltrato intrafamiliar. Aunque resuelve el caso por la vulneración al debido proceso en la valoración de las pruebas, olvidó analizar de qué manera el sesgo de género que imperó en los funcionarios y jueces había afectado la protección de los derechos de la víctima, así 
Como estrategia para superar el riesgo de caer en «el género como retorica», el debido proceso con enfoque de genero debe ir acompañado de una metodología feminista que dé sentido a la interpretación del derecho y que oriente la toma de decisión situando a las mujeres, sus realidades y sus necesidades en sus vivencias frente al derecho y la autoridad estatal, para lo cual analizaremos el método del posicionamiento de Katharine Bartlett.

\section{El método feminista del posicionamiento de Bartlett}

En el proceso judicial con enfoque de género es relevante documentar las distintas formas de opresión que sufren las mujeres con el fin de situar la exclusión, opresión y subordinación que las determinan, lo que en el derecho a la debida diligencia se denomina investigación en contexto. A continuación, analizaremos un método jurídico feminista denominado «el posicionamiento», propuesto por la académica estadounidense Katharine Bartlett. El método del posicionamiento ha sido definido por su autora como «un concepto de verdad no arbitraria basado en la experiencia, no obstante, debido a que se estima que la verdad es algo situado y provisional más que algo externo o final, obliga a las feministas a usar sus métodos para seguir extendiendo y transformando esta verdad» ${ }^{35}$.

El énfasis que los distintos feminismos suelen atribuirle a la experiencia busca evitar las interpretaciones universalistas y apartadas de la realidad que, bajo el manto de neutralidad del derecho, oculta las relaciones de opresión basadas en el género en circunstancias concretas.

En este sentido, el método del posicionamiento pretende nutrirse de otros métodos ya explorados por las feministas como son: i) la pregunta por la mujer; ii) el razonamiento práctico feminista y por último, iii) el aumento de conciencia.

i. En el primero de ellos, la pregunta por la mujer pretende poner de presente cómo lo sustancial del derecho puede «silenciosamente y sin justificación» albergar conceptos, prácticas, ideas, concepciones discriminatorias contra las mujeres. Para lo cual se torna aconsejable que los operadores jurídicos se cuestionen en forma regular un grupo de preguntas: ¿quién hace qué?, ¿cómo, con qué?, ¿quién es dueño de qué?, ¿quién es responsable de qué?, ¿quién tiene derecho a qué?, ¿quién decide qué?, ¿quién recibe qué?, ¿por qué? ¿cuál es la base de la situación? $3^{36}$. Esto nos permite identificar qué consecuencias -implicaciones genéricas, dice Bartlett-,

como analizar de qué manera las practicas aquí evidenciadas y tan recurrentes, contribuían a la perpetuación de los estereotipos de género. Por ejemplo, obviar el material probatorio que recogía la vulneración de los derechos de la víctima como eran los informes sicológicos de medicina legal; la reincidencia en el quebrantamiento de las medidas de protección provisionales y la persistencia en la misma alternativa claramente ineficaz por parte de la Comisaría de Familia y la alta credibilidad que se le dio a la declaración del inculpado frente a duda que generaba las pruebas documentales aportadas por la actora. Al respecto ver la interesante aclaración de voto de los Magistrados Alberto Rojas Ríos y Luis Ernesto Vargas Silva.

${ }^{35}$ BARTLETT, Katharine, «Métodos jurídicos feministas», en: Métodos feministas en el derecho, Aproximaciones críticas a la jurisprudencia peruana. Marisol Fernández yFelix Morales (coordinadores). Palestra, Lima, 20II, p. 20.

${ }^{36}$ Estas preguntas se encuentran sugeridas en: ARBELÁEZ, Lucia; RuIZ, Esmeralda y otras, Criterios de equidad para una administración de justicia con perspectiva de género. Comisión Nacional de Género de la Rama Judicial, Consejo Superior de la Judicatura, Bogotá, agosto 20II, p. 20. 
arrojan las supuestas normas sociales o prácticas neutrales y objetivas. Tales preguntas proceden en todos aquellos casos en que una mujer se encuentre en medio de un conflicto jurídico y tal vez pueda tratarse de un asunto que requiera ser tratado con enfoque de género por cuanto podrían tratarse de normas «masculinas» en un sentido específico, que merecen ser no solo reveladas sino corregidas en tanto persisten en la subordinación de las mujeres y de otros grupos excluidos.

ii. Por su parte, el razonamiento práctico feminista expande las nociones abstractas de relevancia legal y universal a aquellas hasta ahora inexploradas por la doctrina legal, pero que ocurren en la experiencia femenina en el sentido práctico de la vida, conforme a un contexto concreto. En suma, se trata de un razonamiento contextualizado. Esta forma de razonar se nutre del modelo clásico aristotélico de la deliberación, en donde los conflictos no son dicotomizados, sino explorados como dilemas con múltiples perspectivas, contradicciones e inconsistencias, en el que no basta con la implementación de un principio superpuesto a otros para su resolución, sino que requiere tanto de «integraciones imaginativas y reconciliaciones» ${ }^{37}$ que den luz a lo hasta ahora considerado «insignificante», así como de un enfoque feminista para identificar y tomar en cuenta las perspectivas de los excluidos.

iii. Por último, el aumento de conciencia ofrece una manera de evaluar la validez de los principios legales aceptados con el filtro de la experiencia personal de los directamente afectados en la aplicación de tales principios, para en forma interactiva y colaborativa, identificar patrones, construir significados o sentidos comunes. Así, lo que es experimentado como un daño personal individualmente sufrido pasa a ser, mediante la narrativa compartida, en una experiencia colectiva de opresión que puede ser nombrada, interpelada y enjuiciada. Experiencias como la violación marital, la pornografía, el acoso sexual, los ataques en la calle y otras formas de opresión y exclusión normalizadas han sido, mediante el aumento de la conciencia femenina, percibidas en forma distinta por la sociedad.

El posicionamiento es definido por Bartlett como «una postura desde la que un número de verdades aparentemente inconsistentes tienen sentido»; donde el conocimiento y la epistemología de este punto de vista se construyen desde la experiencia individual -la percepción- que tras ser compartida cobra sentido.

Estas verdades son: situadas en tanto emergen desde implicaciones y relaciones particulares que son las que definen la perspectiva del individuo y proveen el lugar para el significado, la identidad y el compromiso político (no basadas en razones esencialistas o innatas); y parciales, en la medida que las perspectivas individuales que las producen y juzgan son incompletas, producto de los contextos sociales entretejidos por la raza, el género, la clase, orientación sexual, etc. Así Bartlett explica que el significado del embarazo no se deriva solamente de sus características biológicas, sino del lugar social que ocupa desde la experiencia vivida por cada mujer según las estructuras del mercado laboral, los acuerdos domésticos, los sistemas de responsabilidad civil, las escuelas, las prisiones, y

\footnotetext{
${ }^{37}$ RoRTY, Amelie, Mind in action, I988, p. 272; citada por Bartlett, p. 55.
} 
otras instituciones sociales que construyen su significado, su verdad del embarazo. De suerte que el compromiso y la acción política feministas que se derivan del posicionamiento produce también compromisos provisionales, abiertos a nuevas experiencias de conocedores que permitan ampliar su espectro de aceptación; compromisos que además están sujetos a una mayor evaluación y revisión crítica. En este aspecto, Bartlett coincide con la mirada postmoderna de la construcción de la verdad. Empero, es plenamente consciente que esa verdad atomizada es limitada, y puede y debe ser mejorada a partir del esfuerzo por trascenderla, entendiendo otras perspectivas -incluidas las masculinas-, poniéndose en el lugar del otro, expandiendo las fuentes de identidad mediante la autodisciplina. Ello no supone que el posicionamiento pretenda reconciliar todas las verdades o los intereses en juego, pero sí busca hacer compromisos con los métodos feministas existentes, dejando la puerta abierta a perspectivas aún inexploradas y que podrían alterar dichos compromisos. Este doble propósito podría resumirse en el compromiso autocrítico en el que las verdades plurales sobre las que actúa Bartlett están sujetas a un mayor refinamiento, ajuste y corrección ${ }^{38}$. Así las discrepancias actuales sobre los temas ya habituales de la sociedad y entre las feministas como el aborto, la pornografía, la custodia infantil, el acoso sexual, entre muchos más, son para la autora en mención conflictos de valor en términos de la existencia social. En donde unas realidades sociales se estiman mejor no porque se validen en comparación con verdades morales externas descubiertas o esenciales- sino por lo que denomina verdades internas que tienen mayor sentido de experiencia y existencia social.

Ahora bien, Bartlett no resuelve cómo ante verdades internas valiosas, únicas y personales distintas, cuál de ellas predominará cuando éstas resultan irreconciliables. Al parecer, desde la mirada de la autora las verdades sociales surgirán de las relaciones sociales y de su examen crítico. Aunque no precise qué método de deliberación sea el adecuado, bajo qué reglas o sin ellas, ni cuáles serían los límites del debate o qué virtudes o características deben rodear a las personas que deliberan, al menos queda claro que los sujetos del debate deben gozar de pensamiento autocrítico.

Bartlett arguye que el método del posicionamiento resiste los intentos de clasificarlo como esencialista o relativista, en tanto que, si bien rechaza una verdad universal, final $u$ objetiva, el posicionamiento exige que tales conocimientos parciales busquen continuamente lo común con aquellos que tienen otra perspectiva: «entender la diversidad humana es también entender las similitudes entre los humanos» ${ }^{39}$. Se trata de un esfuerzo que culmina siendo el fundamento de un mayor conocimiento tanto de la diversidad individual como de la similitud de la humanidad, necesariamente interdependiente.

En breve, el método del posicionamiento parte formulando la pregunta por la mujer, al tiempo que permite a los intérpretes poner en cuestión la aparente neutralidad y objetividad del derecho y con ello descubrir las distintas formas de afectación a las mujeres desde las reglas jurídicas. El razonamiento práctico feminista crea un puente entre los principios con pretensión de universalidad y la lectura contextualizada de la experiencia

\footnotetext{
${ }^{38}$ BARTLETT, Katharine, «Métodos jurídicos feministas», cit., p. Io8.

${ }^{39}$ BARTLETT, ibídem, p. IIz.
} 
compartida de las mujeres y otros colectivos desaventajados, que da sentido a tales principios. Al razonar a partir del contexto y del aumento de conciencia, los métodos feministas tradicionales amplían sus horizontes de análisis al permitirse descubrir y tratar nuevas formas de opresión y exclusión a las mujeres. Por último, el entendimiento posicional pone el énfasis en la práctica crítica permanente como forma de deconstrucción y renovación interna hacia el planteamiento de nuevas preguntas, a conocimientos parciales mejorados, a un derecho más justo y métodos aún más críticos.

\section{Conclusión}

En el presente artículo he analizado como el debido proceso con enfoque de género es un concepto complejo que envuelve una triple dimensión: procedimental, sustancial y metodológica, que lejos de desafiar una noción central del derecho como es el derecho fundamental del debido proceso, al articularse con el género da lugar a una renovación, resignificación y plasticidad de su contenido, mucho más consciente y dialogante con la realidad que determina la toma de decisión judicial, administrativa o disciplinaria.

Además, he defendido que para proteger los derechos de las mujeres no basta con hacer un recuento positivista sobre las normas que así lo reclaman, sino que a su vez, el operador judicial debe implicarse en la resolución del caso entrando más allá de la dermis normativa para comprender en qué forma el derecho y las prácticas judiciales, y en especial la probatoria, reproduce o no los roles sociales y estereotipos que oprimen a las mujeres afectando el acceso a la justicia y el derecho a una decisión justa.

De igual modo, he sostenido que la implementación del método feminista del posicionamiento contribuye a superar el sofisma del género como retórica para introducir la pregunta por la mujer, el análisis en contexto y el pensamiento práctico como una hermenéutica abierta e incompleta que se nutre de la experiencia femenina, de sus vivencias y sentimientos en su relación con el derecho y las practicas que lo hacen efectivo.

\section{Bibliografía}

ARbELÁEZ, Lucía; RuIZ, Esmeralda y otra, Criterios de equidad para una administración de justicia con perspectiva de género. Comisión Nacional de Género de la Rama Judicial, Consejo Superior de la Judicatura, Bogotá, agosto 20 II.

BARTLETT, Katharine, «Métodos jurídicos feministas», en: Métodos feministas en el derecho, Aproximaciones críticas a la jurisprudencia peruana. Marisol Fernández/Félix Morales (coordinadores), Palestra, Lima 2011.

BuTLER, Judith, Deshacer el género. Paidós Studioi67, Barcelona, 2006.

Соок, Rebecca y CuSACK, Simone. Estereotipos de género, Perspectivas legales transnacionales. University of Pennsylvania Press, Traducción de Andrea Parra, Profamilia, Bogotá, 2009.

CRENSHAW, Kimberlé, «Mapping the margins: Intersectionality, identity politics, and violence against women of color». Stanford Law Review, 43, july I99I, pp. I24I-I299.

CuAdros FerRé, Isabel, «Introducción, ¿Por qué no vemos la violencia contra los niños?», en: Evaluación médica del abuso sexual infantil, Una guía práctica. Martin A. Finkel y Angelo P. Giardino; American Academy of Pediatrics, 2009. Traducción autorizada de la Asociación Afecto contra el maltrato infantil, Bogotá, D.C., 20I5. 
CURIEL PiCHARDo, Ochy, «Construyendo metodologías feministas desde el feminismo decolonial», En: Otras formas de (Re)conocer, Reflexiones, herramientas y aplicaciones desde la investigación feminista. Irantzu Mendia Azkue, Marta Luxán, Matxalen Legarreta, Gloria Guzmán, Iker Zirion, Jokin Azpiazu Carballo (eds.), Universidad del País Vasco, Donostia-San Sebastián, 2014 .

Fraser, Nancy, Las escalas de la justicia. Pensamiento Herder dirigida por Manuel Cruz, Barcelona, 2008.

FUndACIÓn PlAN, Relatoría, Evento «Por una respuesta judicial Adecuada», organizado por el Consejo de Estado el 23 de Noviembre del 2017 en Bogotá D.C.

GAUTHIER, Florence, «Olympe de Gouges: ¿historia o mistificación?», en: Sin permiso, República $\gamma$ Socialismo también para el S. XXI; edición de I6/03/20I4, http://www.sinpermiso.info/ textos/olympe-de-gouges-historia-o-mistificacin, página revisada el 20/04/I7.

MALGeSini, Graciela Y GiménEZ, Carlos, Guía de conceptos sobre migraciones, racismo e interculturalidad. Catarata, Madrid, 2000.

MC PheE, Peter, La Revolución Francesa, 1789-1799. Una nueva historia. Crítica, Libros de historia, Barcelona, 2002.

Martín Casares, Aurelia, Antropología del género. Culturas, mitos y estereotipos sexuales. Cátedra, Universitat de Valencia, Instituto de la Mujer, Madrid, 2008.

QUINCHE R. Manuel Fernando, Vías de hecho. Acción de tutela contra providencias. Ed. Ibañez y Pontificia Universidad Javeriana, Bogotá, 2012.

Rodriguez PeÑARAndA, María Luisa, «Dejando atrás la constitución del litigio incluyente: el reto de la paz como bienestar social». Revista Pensamiento Jurídico, 43, enero-junio 20I6, pp. 349-375.

SAlter, Anna C., Predators, pedophiles, rapists, a other sex offenders: who they are, how they operate, and how we can protect ourselves and our children. Basic Books, New York, 2003.

SCOTT, Joan, «El género: una categoría útil para el análisis histórico», en: El género: la construcción cultural de la diferencia sexual. Lamas Marta, Compiladora, PUEG, México.

Mohanty, Chandra, «Bajo los ojos de occidente. Academia Feminista y discurso colonial», en: Descolonizando el Feminismo: Teorías y Prácticas desde los Márgenes. Liliana Suárez Navaz y Aída Hernández (editoras). Cátedra, Madrid, 2008.

Viveros, Mara, «La interseccionalidad, una aproximación situada a la dominación», Revista Debate Feminista, 52, 20I6, pp. I-I7. Disponible en http://debatefeminista.cieg.unam.mx/.

VIVERos, Mara y ZAMBRANO, Marta, «La diferencia: un concepto problemático para la antropología y el feminismo», en: El género: una categoría útil para las ciencias sociales. Luz Gabriela Arango Gaviria, Mara Viveros Vigoya (Editoras). Colección Estudios de Género, Facultad de Ciencias Humanas, Universidad Nacional de Colombia, Bogotá, 20 I3. 